\title{
Off-Pump Reimplantation of Anomalous Origin of the Right Coronary Artery
}

\author{
Masahiro Endo, MD; Hiroshi Nishida, MD; Yasuko Tomizawa, MD; \\ Hitoshi Koyanagi, MD; Tomizo Hiekata, MD*
}

\begin{abstract}
A 30-year-old man was diagnosed to have an anomalous origin of the right coronary from the pulmonary artery. Through a mini-sternotomy, without extracorporeal circulation, reimplantation of the anomalous origin of the right coronary artery from the pulmonary artery to the aorta was successfully performed. This is a successful case of off-pump cardiac correction of this type of isolated anomaly, using a minimally invasive approach. (Jpn Circ J 2001; 65: 471-472)
\end{abstract}

Key Words: Cardiovascular abnormalities; Congenital heart defects; Coronary vessel anomalies

A $\mathrm{n}$ anomalous origin of the right coronary artery from the pulmonary artery is rare compared to BlandWhite-Garland syndrome! With understanding of the anatomy and physiology of the anomalous vessel, offpump reimplantation of the anomalous origin of the right coronary from the pulmonary artery to the aorta was successfully performed through a mini-sternotomy.

\section{Case Report}

A 30-year-old man was referred to the outpatient clinic for evaluation of to-and-fro murmur, which was first noted at age 7 years. Physical examination and chest X-ray showed no specific changes. A treadmill stress electrocardiograph (ECG) was positive for ischemia (Fig 1) with chest oppression. By right heart catheterization, a left-to-right shunt was detected (Qp/Qs 1.58). Coronary angiography showed the right coronary artery (RCA) filled retrogradely from the left side, and flow of contrast material into the pulmonary artery was visible (arrow, Fig 2A). The location of the ostium of the RCA was extremely high and it originated from the right side of the pulmonary artery. Images from transesophageal echocardiography confirmed the findings (arrow, Fig 2B).

Surgical correction was performed through an upper mini-sternotomy (Fig 2C). The ostium of the enlarged tortuous thin-walled RCA was recognized $25 \mathrm{~mm}$ above the free margin of the pulmonary valve. The mean flow of the RCA was measured by a magnetic flow meter as 1,500 $\mathrm{ml} / \mathrm{min}$ in the direction toward the pulmonary artery. The proximal portion of the RCA was mobilized free carefully from fatty tissue around and collateral vessel. The RCA was clamped distally by a micro bulldog clamp. The proximal portion of the RCA was simply ligated and excised. The

(Received November 27, 2000; revised manuscript received December 25, 2000; accepted January 9, 2001)

Department of Cardiovascular Surgery, The Heart Institute of Japan, Tokyo Women's Medical University and *Department of Surgery, St Marianna University School of Medicine, Tokyo, Japan

Mailing address: Masahiro Endo, MD, Department of Cardiovascular Surgery, The Heart Institute of Japan, Tokyo Women's Medical University, 8-1 Kawada, Shinjuku, Tokyo 162-8666, Japan. E-mail: ENDO@hij.twmu.ac.jp
RCA was reimplanted into the aortic root, using a partialocclusion clamp, and the flow decreased to $270 \mathrm{ml} / \mathrm{min}$.

A postoperative angiogram showed normally directed coronary blood flow and diminished intercoronary anastomosis (Fig 2D). The postoperative course was uneventful and the patient was discharged with complete disappearance of symptoms.

\section{Discussion}

An anomalous origin of the RCA from the pulmonary artery is occasionally found at autopsy and angiography, and is incidentally noted during open heart surgery for other cardiac defects. Because the course and peripheral distribution of the RCA are normal in isolated cases, this anomaly generally does not cause any typical clinical findings. The prognosis of this anomaly is much better than that of Bland-White-Garland syndrome, and a limited number of sudden deaths ${ }^{2,3}$ and cardiac arrest during dancing ${ }^{4}$ have

TREADMILL EXERCISE TESTS (BRUCE)

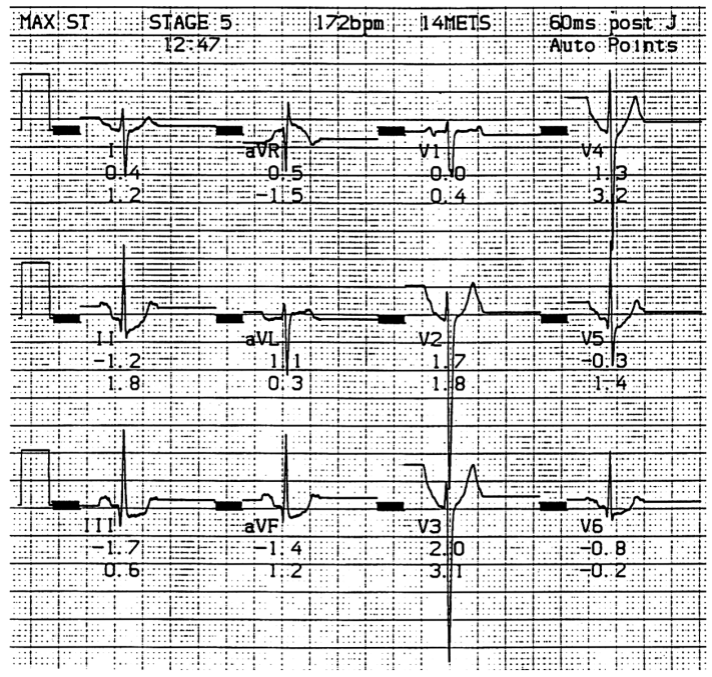

Fig 1. Treadmill stress electrocardiograph. ST-segment depression was demonstrated in II, III and aVF. 


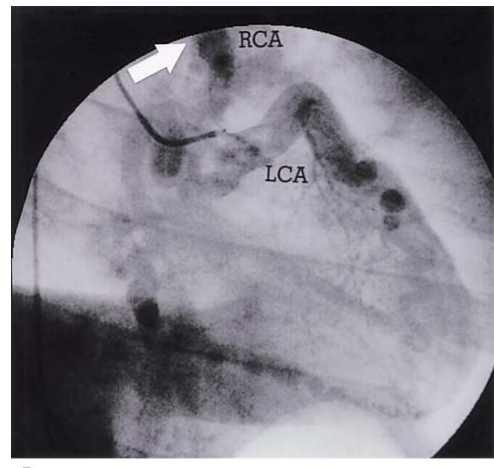

A

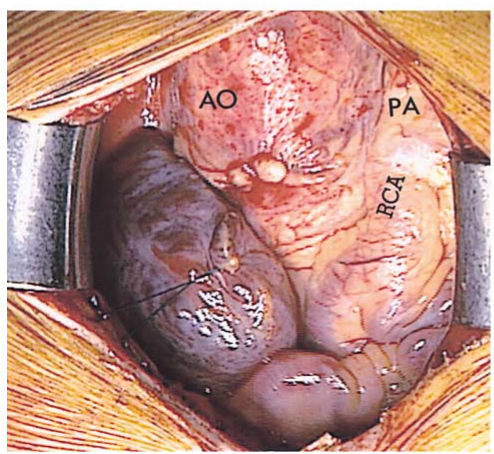

C

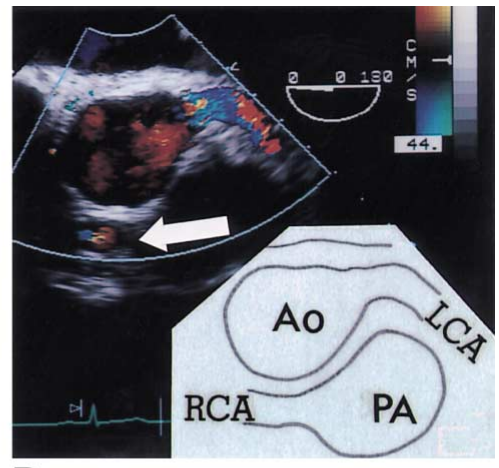

B

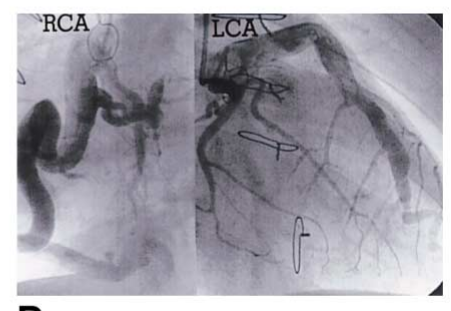

Fig 2. (A) Preoperative coronary angiography. An enlarged left coronary artery (LCA) with collateral circulation to the right coronary artery (RCA) was observed. (B) Transesophageal echocardiography. (C) Operative view through upper mini-sternotomy. An enlarged tortuous thin-walled right coronary artery (RCA) originated from the pulmonary artery (PA). The aorta (AO) was in the middle of the surgical field. (D) Postoperative coronary angiography. been reported.

Myocardial damage and anginal pain have been reported rarely in this isolated anomaly. However, evidence of cardiac ischemia with exercise was well recognized by a treadmill stress ECG in the present case. Simple ligation of the anomalous vessel was not recommended as treatment because right coronary flow was $270 \mathrm{ml} / \mathrm{min}$ after reimplantation and postoperative intercoronary anastomoses were diminished in this case. Bypass grafting using the saphenous vein after ligating the RCA was introduced. However, we believe that reimplantation of the RCA into the aorta is the most promising technique, which is aimed at creating a normal 2-coronary arterial system5

Understanding the anatomy of the spiral septum dividing the primitive undivided truncus is important, and an upper mini-sternotomy was applied. When coronary take-off is high, it originates from the pulmonary side of the truncus. Conversely, when a coronary artery arises low, it originates from the aortic segment? Direct reimplantation could be accomplished in such a small surgical field because the length of the anomalous vessel and its origin in relation to the aortic root was short. When the proximal segment of the anomalous artery had been dissected free, it was apparent that direct anastomosis to the aorta would be possible.

Off-pump reimplantation with a full sternotomy was applied by Bregman et $\mathrm{al}^{4}$ and Tingelstad et $\mathrm{al}^{5}$ in similar cases of anomaly, and it was our understanding that simple occlusion without extracorporeal circulation would be safe in the present case. Before correction, flow of the RCA was in the direction toward the pulmonary artery, establishing a left-to-right shunt. However, postoperative angiography showed a normally directed coronary flow. This is a successful case of a minimally invasive approach and off-pump cardiac correction for this isolated anomaly.

\section{References}

1. Endo M, Takayasu S, Obunai Y, Nakazawa M, Konno S: Anomalous origin of left coronary artery from pulmonary artery. $J$ Thorac Cardiovasc Surg 1974; 67: 896-902

2. Wald S, Stonecipher R, Baldwin BJ, Nutter DO: Anomalous origin of the right coronary artery from the pulmonary artery. Am J Cardiol 1971; 27: 677-681

3. Ross TC, Latham RD, Craig WE: Anomalous origin of the right coronary artery from the main pulmonary artery: Incidental finding in a case of dilated cardiomyopathy. South Med J 1987; 6: 783-786

4. Bregman D, Brennan FJ, Singer A, Vinci J: Anomalous origin of the right coronary artery from the pulmonary artery. J Thorac Cardiovasc Surg 1976; 72: 626-630

5. Tingelstad JB, Lower RR, Eldredge WJ: Anomalous origin of the right coronary artery from the main pulmonary artery. Am J Cardiol 1972; 30: 670-673

6. Blake HA, Manion WC, Mattingly TW, Baroldi G: Coronary artery anomalies. Circulation 1964; 30: 927-940 